Supplemental Information

for

\title{
Structural and Biochemical Characterization of 6-Hydroxynicotinic Acid 3- Monooxygenase, A Novel Decarboxylative Hydroxylase Involved in Aerobic Nicotinate Degradation
}

Katherine A. Hicks, ${ }^{\#, *}$, Meigan E. Yuen\#, Wei Feng Zhen", Tyler J. Gerwig^, Ryan W. Story , Megan C. Kopp ${ }^{\S, \dagger}$, and Mark J. Snider ${ }^{\wedge}$,

${ }^{\#}$ Department of Chemistry, SUNY Cortland, Cortland, New York 13045, United States

Department of Chemistry, The College of Wooster, Wooster, Ohio 44691, United States

${ }^{\S}$ Department of Chemistry and Chemical Biology, Cornell University, Ithaca, New York 14853, United States

${ }^{*}$ Corresponding Author.

†Present Address: Department of Life Sciences, Centre for Structural Biology, Sir Ernst Chain Building, Imperial College London, London SW7 2AZ, UK.

\section{Table of Contents:}

Table S1. Effects of pre-incubation of $B b \mathrm{NicC}$ with iodoacetamide and MMTS on catalytic turnover.

Table S2. Enzymes Identified as Structurally Similar to $P p N i c C$ based on DALI.

Figure S1. LC-ESI-MS ion chromatograms analyzing for the presence of $\mathrm{m} / \mathrm{z}$ ion of 112.1 in the products of the reaction of purified Bb1770 with 6-HNA and NADH.

Figure S2. Effect of solution ionic strength on $\mathrm{BbNicC}$ catalysis. 
Table S1. Effects of pre-incubation of $B b \mathrm{NicC}$ with iodoacetamide and MMTS on catalytic turnover

\begin{tabular}{|c|c|}
\hline Modification & $\boldsymbol{k}_{\text {cat }}\left(\mathbf{s}^{-1}\right)$ \\
\hline none & 5.3 \\
\hline none then post-incubation with DTT $(150 \mu \mathrm{M})$ & 5.3 \\
\hline+ iodoacetamide $(34 \mu \mathrm{M})$ & 3.2 \\
\hline+ iodoacetamide $(34 \mu \mathrm{M})$ then post-incubation with DTT $(150 \mu \mathrm{M})$ & 2.7 \\
\hline+ MMTS $(34 \mu \mathrm{M})$ & 3.0 \\
\hline & 4.9 \\
\hline
\end{tabular}


Table S2. Enzymes Identified as Structurally Similar to $P p N i c C$ based on DALI.

\begin{tabular}{|l|c|c|c|c|c|}
\hline Protein & $\begin{array}{l}\text { PDB } \\
\text { ID }\end{array}$ & Z Score & RMSD & \% Identical & \# aligned residues \\
\hline $\begin{array}{l}\text { 3-hydroxybenzoate 6-hydroxylase } \\
\text { (3HB6H) }\end{array}$ & 4BJZ & 40.0 & 2.2 & 30 & 339 \\
\hline HpxO & 3RP7 & 38.2 & 2.3 & 27 & 337 \\
\hline $\begin{array}{l}\text { 2-methyl-3-hydroxypyridine-5- } \\
\text { carboxylic acid oxygenase (MHPCO) }\end{array}$ & 3GMC & 35.8 & 2.7 & 20 & 331 \\
\hline Salicylate hydroxylase (SALH) & 5EVY & 34.5 & 2.5 & 28 & 411 \\
\hline $\begin{array}{l}\text { 2,6-dihydroxypyridine 3-hydroxylase } \\
\text { (DHPH) }\end{array}$ & 2VOU & 34.4 & 2.5 & 24 & 324 \\
\hline $\begin{array}{l}\text { p-hydroxybenzoate hydroxylase } \\
\text { (PHBH) }\end{array}$ & 1YKJ & 31.3 & 3.0 & 20 & 328 \\
\hline
\end{tabular}



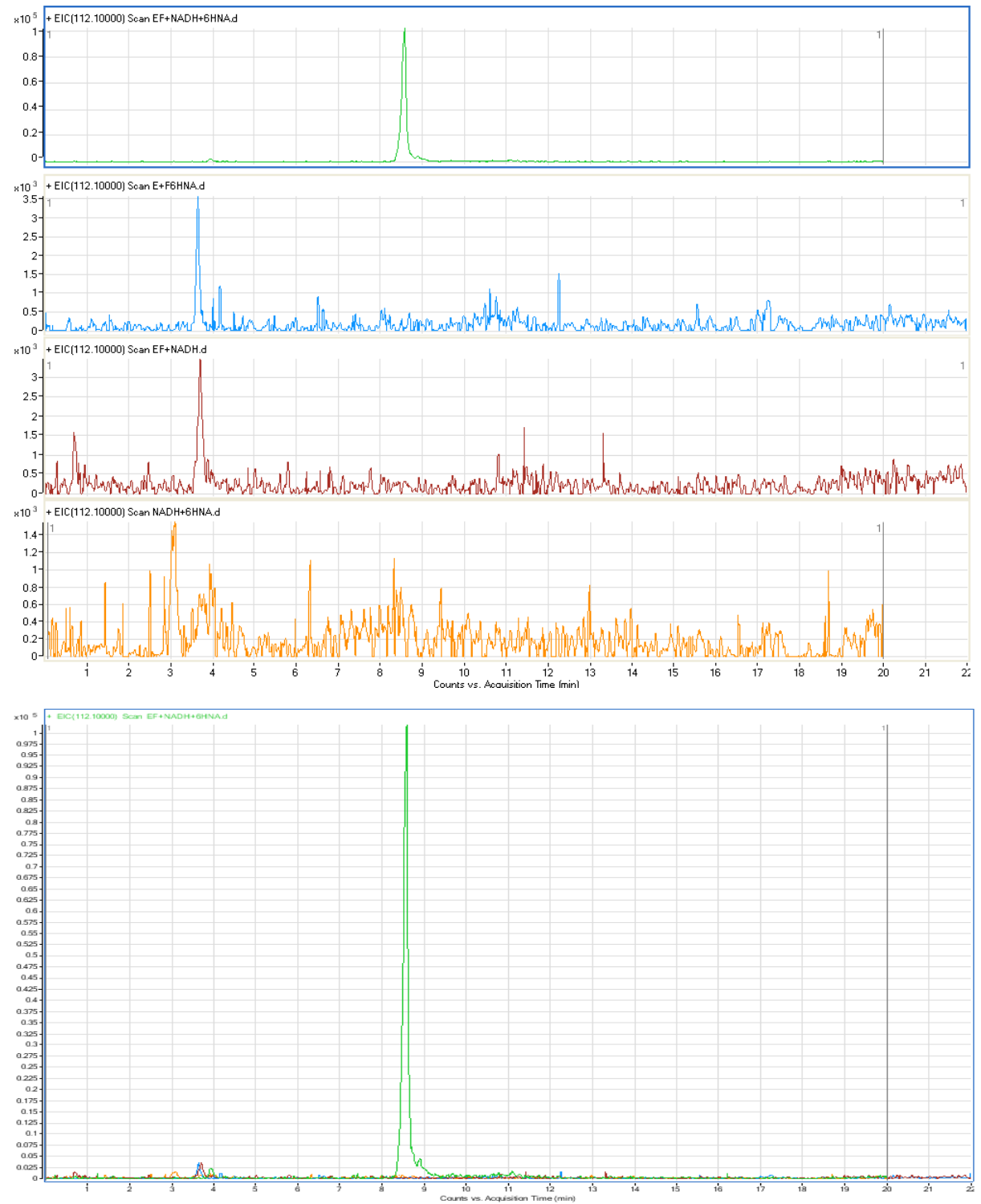

A: $B b \mathrm{NicC}(1 \mu \mathrm{M}), \mathrm{NADH}$

(1mM), 6-HNA (5 mM)

B: $B b \mathrm{NicC}(1 \mu \mathrm{M}), 6-\mathrm{HNA}(5 \mathrm{mM})$

C: $B b \mathrm{NicC}(1 \mu \mathrm{M}), \mathrm{NADH}(1 \mathrm{mM})$

D: NADH (1mM), 6-HNA (5 mM)

E: Overlay of chromatograms A, $\mathrm{B}, \mathrm{C}$ and $\mathrm{D}$ (from above)

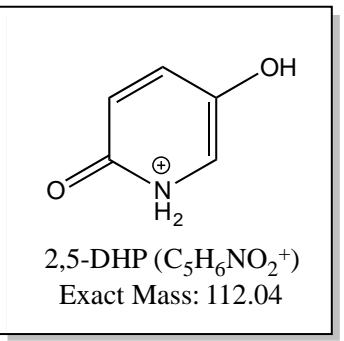

Figure S1. LC-ESI-MS extracted ion chromatograms analyzing for the presence of $\mathrm{m} / \mathrm{z}$ ion of 112.1 in the products of the reaction of purified Bb1770 with 6-HNA and NADH. Samples were incubated at $25^{\circ} \mathrm{C}$ in sodium phosphate buffer $(\mathrm{pH} 7.5,20 \mathrm{mM})$ for $1 \mathrm{hr}$ and filtered through Micron YL-10 centrifugal filters before LC. Products of the enzyme assays were separated on Ascentis C18 column (Supelco Analytical) using aqueous $0.1 \%$ formic acid and eluted with a linear methanol gradient (0-50\% over $10 \mathrm{~min})$. Components of each enzyme assay sample listed beside each chromatogram above, in which chromatogram A contains the full assay expected to generate 2,5-DHP, chromatograms B, C, and D show the results of negative controls, and chromatogram $\mathrm{E}$ is an overlay of each chromatogram to better illustrate the relative abundance of the $112.1 \mathrm{~m} / \mathrm{z}$ ion. Mass data collected with an Agilent 6410 triple quadrupole mass spectrometer in positive ion mode. Elution time (matching a standard 2,5-DHP sample) and $\mathrm{m} / \mathrm{z}$ ion detected are consistent with the formation of 2,5DHP from 6-HNA and NADH in the presence of the purified enzyme. Results show that the Bb1770 gene codes for a functional 6-hydroxynicotinate 3-monooxygenase (NicC). 


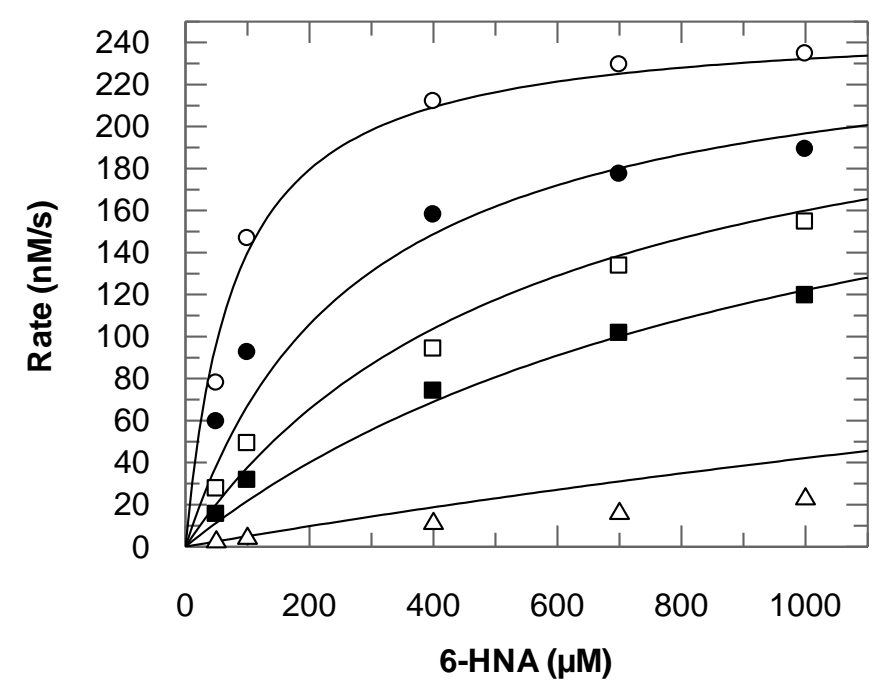

Figure S2. The effect of increasing concentration of $\mathrm{NaCl}(0-250 \mathrm{mM})$ was measured in sodium phosphate buffer (10 mM, pH 7.5) using a constant concentration of NADH (100 $\mu \mathrm{M})$ and $\mathrm{BbNicC}(50 \mathrm{nM})$ while varying the concentration of 6-HNA $(50-1000 \mu \mathrm{M})$. Initial rate data were fit globally to the competitive inhibition model (Eq. S1) to determine the value of $K_{i}^{\mathrm{NaCl}}=4.1 \pm 0.7 \mathrm{mM}$.

$$
\text { Eq S1: } \quad v=\frac{k_{c a t}[E][S]}{K_{M}+\left(1+\frac{[l]}{K_{I}}\right)+[S]}
$$

The global fit of inhibition by $\mathrm{NaCl}[0(\triangle), 10 \mathrm{mM}(\square), 25 \mathrm{mM}(\square), 50 \mathrm{mM}(\bullet), 250 \mathrm{mM}$ (O)] on $\mathrm{BbNicC}$ activity resulted in $K_{i}^{\mathrm{NaCl}}=4.1 \pm 0.7 \mathrm{mM}$. 